\section{Taking the stress out of dental recruitment}

\author{
Kate Quinlan talks to James Richards, Classified Advertising Manager for \\ The BDJ Portfolio, about the challenges faced by practice owners when \\ recruiting and the relaunch of $B D J$ Jobs.
}

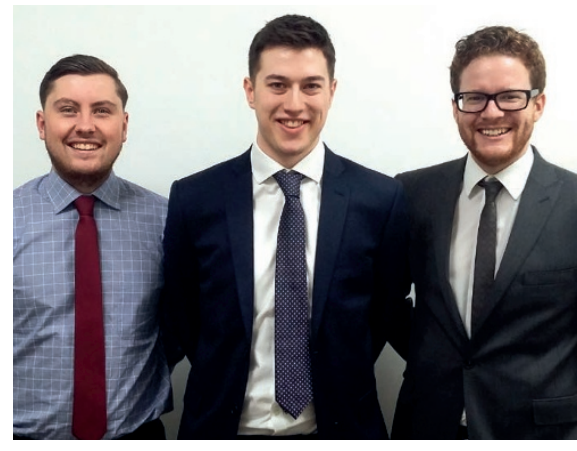

Left to right - Chris Feek, Jamie King and James Richards of $B D J$ Jobs

throughout the early twenty-first century, so too did the traffic to BDJ Jobs. I spoke to James Richards, Classified Advertising Manager for The BDJ Portfolio, to find out more about the brand new version of the website.

James has worked on the BDJ Classified team since 2008, and is assisted in Classified Media Sales by James 'Chris' Feek and James 'Jamie' King: collectively known as BDJames to the wider team. James $F$ and $K$ were given their nicknames by James $R$ to avoid confusion among clients.

Why has BDJ Jobs relaunched?

JR: During the last 3-4 years there has been a real shift from print to online. We knew that a significant proportion of our advertisers wanted to go online only and with the new $B D J$ Jobs we can now offer that to them.

People want the immediacy of online and that is really the benefit of BDJ Jobs. Print is still the right way to go for many clients - and the $B D J$ is great for this as it's published every two weeks - but if someone wants to recruit a position immediately, online is the way to go.

Publishing online has a lot of benefits; it is more accessible and these days anyone can access the Internet from their phone or tablet. The old BDJ Jobs website already had nearly $50 \%$ of its traffic from mobile devices. As the new site is mobile-optimised, this figure has gone way over $50 \%$. Employers can even post jobs from their phones, if they want to.

The new BDJ Jobs site features some other great new functionality for jobseekers too such as job alerts. This means that if a dentist wants to find a job in a particular area, that job is automatically emailed directly to them.

Alongside BDJ Jobs we have also launched BDJ Marketplace, which is for every other kind of classified advertisement besides jobs. 
It features practices for sale or rent, postgraduate education, courses for DCPs, financial and legal services, referrals; and even dating! We even offer a section for used equipment, where BDA members can advertise for as little as $£ 10$ per post.

Unlike other jobs boards, $B D J$ Jobs is owned by the British Dental Association, so the money dentists spend with BDJ Jobs is reinvested in the $\mathrm{BDA}$, who support the UK dental industry and dental professionals in a multitude of ways.

What features does the new website have that the old one didn't?

JR: For the first time the website is automated, so it's really easy for people to go online and post adverts themselves. There are lots of improvements that can help jobseekers with their job search - users can make a professional application from their mobile phones; they can upload their $\mathrm{CV}$, which makes applications easier; they can save relevant jobs and reply to them later; there is the career advice section; and there is now geographical targeting - so if a dentist wanted to apply for a job near their home they can just put in their home postcode and search for jobs in a 5-15 mile radius. There are new filters as well, so that dentists can find exactly what they're looking for, for example they can filter for private practice only or part-time roles.

$B D J$ Jobs is aimed at all dental professionals and our new improved search engine optimisation means that the new website is reaching more people than before. It is certainly reaching more DCPs; a recent client said that he was very pleased to receive applications from two high quality practice manager candidates through placing an advert on BDJ Jobs.

How can the new BDJ Jobs help with the recruitment problems some employers are experiencing?

JR: Jobseekers will see a much wider range of adverts due to the geographical targeting functionality.

Advertisers can also take advantage of the fact that there are no word limits for online ads (unlike print ads, where we charge per word, due to the amount of space the ad takes up in the Journal). This means online adverts can be a lot more effective as employers can write a long descriptive advert. Previously, employers might have written just two sentences: 'London, part-time associate needed, call this number' and they'd get a great response. These days, however, if you're applying for a job you're going to go for the job with lots of information about the location, benefits, hours, team, etc.

How can BDJ Jobs help BDA members in particular?

JR: BDA members receive a $15 \%$ discount if they place an ad, potentially saving up to $£ 100$. We're also helping BDA members by offering them free advertising for dental nurse, practice manager, orthodontic therapist and technician positions. Over the Christmas period we will have some more special offers for BDA members.

How has the new BDJ Jobs site been received?

JR: The special offers have proved very popular with BDA members, and in general there is a huge volume of dentists and DCPs viewing the site each month: around 20,000 unique visitors and 550,000 page views. There are already over 3,000 registered jobseekers on the site and almost 600 registered recruiters. We've had over 13,000 job applications through the site already.

What's your forecast for the dental recruitment industry in 2017 and beyond? JR: I think there'll be an even bigger shift towards online and I think dentists will have to sell their roles more actively, which means thinking about their employer brand a lot more.

We can help with this because everyone who advertises with us now receives a free employer profile, which can be used to really convey what their practice is like as a place to work - it paints a much better picture than just listing what you need in an advert. It's good to show what you can offer. You can add a logo and if you want to upload pictures or a video we can help you do that as well. 'Here's a photo of our team', for example, is very welcoming and helps put faces to names for prospective team members.

One of the key benefits of this new website is that we are now able to advise employers on how to write their adverts for the first time. People are seeing more success from writing detailed job adverts. It doesn't necessarily lead to more applications but it leads to more relevant applications because more information is available upfront which saves both the employer and the jobseeker a lot of time.

Do you have a message for readers? JR: I'd just like to let readers know that our team is here to help you. If you're a jobseeker and you're struggling to use the website, give us a call and we'll explain how to use it effectively. If you're an employer who is having difficulty with recruitment, call or email us and we will help you fill that vacancy.

\section{www.bdjjobs.com}

Telephone: 02078434729 (office hours)

Email:contact@bdjjobs.com

1. British Dental Association. Evidence to the Review Body on Doctors' and Dentists' Remuneration for 2017/18. September 2016. Report available online at https:// www.bda.org/dentists/policy-campaigns/research/workforce-finance/ddrb/Documents/DDRB\%20evidence $\% 20$ 2017-18\%20British\%20Dental\%20Association $\% 20$ FINAL.pdf (accessed November 2016).

\section{From the archive}

The British Dental Journal (BDJ) has featured classified advertisements right from the very beginning. These photos show a page of the Journal published in January 1896 (right, below) and another published 30 years later, in November 1926 (right).

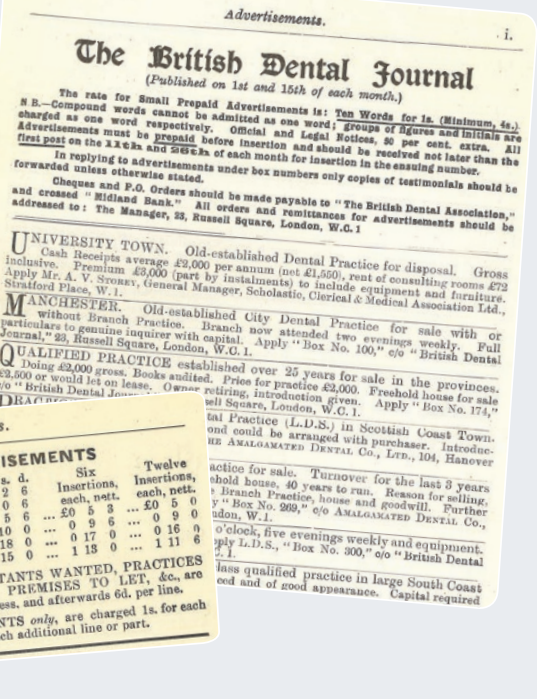

